\title{
Lumbar spondylosis: clinical presentation and treatment approaches
}

\author{
Kimberley Middleton • David E. Fish
}

Published online: 25 March 2009

(C) The Author(s) 2009. This article is published with open access at Springerlink.com

\begin{abstract}
Low back pain (LBP) affects approximately $60-85 \%$ of adults during some point in their lives. Fortunately, for the large majority of individuals, symptoms are mild and transient, with $90 \%$ subsiding within 6 weeks. Chronic low back pain, defined as pain symptoms persisting beyond 3 months, affects an estimated $15-45 \%$ of the population. For the minority with intractable symptoms, the impact on quality of life and economic implications are considerable. Despite the high prevalence of low back pain within the general population, the diagnostic approach and therapeutic options are diverse and often inconsistent, resulting in rising costs and variability in management throughout the country. In part, this is due to the difficulty establishing a clear etiology for most patients, with known nociceptive pain generators identified throughout the axial spine. Back pain has been termed as "an illness in search of a disease." Indeed, once "red flag" diagnoses such as cancer and fracture have been ruled out, the differential sources of low back pain remain broad, including the extensive realm of degenerative changes within the axial spine for which radiological evaluation is nonspecific and causal relationships are tentative. We will elaborate on
\end{abstract}

K. Middleton

Department of Physical Medicine and Rehabilitation,

University of Washington Medical Center, Seattle, WA, USA

D. E. Fish ( $\square)$

Department of Orthopaedic Surgery, Physical Medicine and Rehabilitation, David Geffen School of Medicine at UCLA, 1250 16th Street, 7th Floor Tower Building Room 745, Santa Monica, CA 90404, USA

e-mail: dfish@mednet.ucla.edu these degenerative processes and their clinical implications. We will further discuss diagnostic approaches and the efficacy of existing treatment options.

Keywords Low back pain - Spondylosis - Osteophyte · Degenerative disk disease $\cdot$ Intervertebral osteochondrosis

\section{Introduction}

Low back pain (LBP) affects approximately $60-85 \%$ of adults during some point in their lives [1-3]. Fortunately, for the large majority of individuals, symptoms are mild and transient, with 90\% subsiding within 6 weeks [4]. Chronic low back pain, defined as pain symptoms persisting beyond 3 months, affects an estimated $15-45 \%$ of the population $[5,6]$. For the minority with intractable symptoms, the impact on quality of life and economic implications are considerable [7].

Despite the high prevalence of low back pain within the general population, the diagnostic approach and therapeutic options are diverse and often inconsistent, resulting in rising costs and variability in management throughout the country [8]. In part, this is due to the difficulty establishing a clear etiology for most patients, with known nociceptive pain generators identified throughout the axial spine [9]. Back pain has been termed as "an illness in search of a disease" [10]. Indeed, once "red flag" diagnoses such as cancer and fracture have been ruled out, the differential sources of low back pain remain broad, including the extensive realm of degenerative changes within the axial spine for which radiological evaluation is nonspecific and causal relationships are tentative $[11,12]$.

We will elaborate on these degenerative processes and their clinical implications. We will further discuss the 
diagnostic approaches and the efficacy of existing treatment options.

\section{Tackling the terminology}

The terms lumbar osteoarthritis, disk degeneration, degenerative disk disease, and spondylosis are used in the literature to describe anatomical changes to the vertebral bodies and intervertebral disk spaces that may be associated with clinical pain syndromes.

Spinal osteoarthritis (OA) is a degenerative process defined radiologically by joint space narrowing, osteophytosis, subchondral sclerosis, and cyst formation [13, 14]. Osteophytes included within this definition fall into one of the two primary clinical categories [14]. The first, spondylosis deformans describes bony outgrowths arising primarily along the anterior and lateral perimeters of the vertebral end-plate apophyses. These hypertrophic changes are believed to develop at sites of stress to the annular ligament and most commonly occur at thoracic T9-10 and lumbar L3 levels [15]. These osteophytes have minimal effect on intervertebral disk height [16] and are frequently asymptomatic, with only rare complications arising from their close anatomic relationship to organs anterior to the spine [15].

By contrast, intervertebral osteochondrosis describes the formation of more pathological end-plate osteophytes, associated with disk space narrowing, vacuum phenomenon, and vertebral body reactive changes [16]. If protruding within the spinal canal or intervertebral foramina, these bony growths may compress nerves with resulting radiculopathy or spinal stenosis. Moreover, these bony projections may limit joint mobility and invade other organs or tissues [14]. The term "osteoarthritis" suggests pathology limited to bone. Nevertheless, in this context, it has clear implications for the health of neighboring disks and nerve roots.

Comparatively, degenerative disk disease (DDD) refers to back pain symptoms attributable to intervertebral disk degeneration. Such pathologic changes include disk desiccation, fibrosis, and narrowing. The anulus may bulge, fissure, or undergo mucinous degeneration. Also included within the anatomic definition of DDD are defects and sclerosis of the end-plates, and osteophytes at the vertebral apophyses [16]. With these bony changes included in the radiographic description of both $\mathrm{OA}$ and DDD, there exists diagnostic overlap between the conditions. As a result, these terms are often used interchangeably in the medical literature to describe similar phenomena.

Spondylosis of the lumbar spine, the subject of this paper, is a term with many definitions. In the literature, it has been utilized in many different contexts, employed synonymously with arthrosis, spondylitis, hypertrophic arthritis, and osteoarthritis. In other instances, spondylosis is considered mechanistically, as the hypertrophic response of adjacent vertebral bone to disk degeneration (although osteophytes may infrequently form in the absence of diseased disks) [17]. Finally, spondylosis may be applied nonspecifically to any and all degenerative conditions affecting the disks, vertebral bodies, and/or associated joints of the lumbar spine $[17,18]$. For purposes of this review, we will use this final, broad definition of spondylosis, recognizing the high incidence of coincident degenerative changes, and the dynamic interplay between adjacent disks, vertebra, and nerves that create the clinical pain syndromes within the axial spine and associated nerves.

\section{Epidemiology}

Degenerative spine changes are remarkably common in population studies. Symmons' et al. [19] study of individuals aged $45-64$ years identified $85.5 \%$ of participants to demonstrate osteophytes within the lumbar spine. O'Neill et al. [20] explored osteophytosis within a UK adult population over age 50 years, finding $84 \%$ of men and $74 \%$ of women to demonstrate at least one vertebral osteophyte, with increased incidence among individuals with more physical activity, self reported back pain, or higher BMI scores. Despite marked variability within the population, men appear to have more significant degenerative changes than women, both with regard to number and severity of osteophyte formation [20].

Radiographic evidence of degenerative disease of the lumbar spine among asymptomatic individuals is impressive. MRI imaging in asymptomatic patients over age 60 years reveals disk protrusions in $80 \%$ [21] and degenerative spinal stenosis in $20 \%$ [11]. A study comparing radiographic evidence of spine degeneration among categories of men who were without pain, with moderate pain, or with severe lower back pain found similar frequency of disk space narrowing and bone spurs among all three groups [22].

Furthermore, degenerative changes may appear in young individuals without decades of spine loading. Lawrence [23] found $10 \%$ of women aged 20-29 to demonstrate evidence of disk degeneration. Lumbar spondylosis, while affecting $80 \%$ of patients older than 40 years, nevertheless was found in $3 \%$ of individuals aged 20-29 years in one study [15]. The high incidence of degeneration among young and asymptomatic individuals highlights the challenge involved in establishing causality between imaging findings and pain symptoms in affected patients. 


\section{Pathogenesis}

The high incidence of simultaneous degenerative changes to the intervertebral disk, vertebral body, and associated joints suggests a progressive and dynamic mechanism, with interdependent changes occurring secondary to disk space narrowing [17].

Intervertebral disks are believed to undergo what Kirkaldy Willis and Bernard [24] first coined a "degenerative cascade" (Fig. 1) of three overlapping phases that may occur over the course of decades. Phase I (Dysfunction Phase) describes the initial effects of repetitive microtrauma with the development of circumferential painful tears of the outer, innervated anulus, and associated endplate separation that may compromise disk nutritional supply and waste removal. Such tears may coalesce to become radial tears, more prone to protrusion, and impact the disk's capacity to maintain water, resulting in desiccation and reduced disk height. Fissures may become ingrown by vascular tissue and nerve endings, increasing innervation and the disk's capacity for pain signal transmission [25]. Phase II (Instability Phase) is characterized by the loss of mechanical integrity, with progressive disk changes of resorption, internal disruption, and additional annular tears, combined with further facet degeneration that may induce subluxation and instability. During Phase III (Stabilization Phase), continued disk space narrowing and fibrosis occurs along with the formation of osteophytes and transdiscal bridging [26].

Schneck presents a further mechanical progression, building upon this degenerative cascade of the intervertebral disk, to explain other degenerative changes of the axial spine. He proposes several implications of disk space narrowing. Adjacent pedicles approximate with a narrowing of the superior-inferior dimension of the intervertebral canal. Laxity due to modest redundancy of the longitudinal ligaments enables bulging of the ligamentum flavum and potential for spine instability. Increased spine movement permits subluxation of the superior articular process (SAP), causing a narrowed anteroposterior dimension of the intervertebral and upper nerve root canals. Laxity may also translate into altered weight mechanisms and pressure relationships on vertebral bone and joint spaces believed to influence osteophyte formation and facet hypertrophy to both inferior and superior articular processes with risks for projection into the intervertebral canal and central canal, respectively. Oblique orientations of the articular processes may further cause retrospondylolisthesis, with resulting anterior encroachment of the spinal canal, nerve root canal, and intervertebral canal [17].

Biochemical research exploring osteophyte formation supports the above process. Osteophyte lipping is believed to form at periosteum [27] through the proliferation of peripheral articular cartilage which subsequently undergoes endochondral calcification and ossification [28]. Changing weight mechanics and pressure forces as well as alterations in oxygen tension and dynamic fluid pressure appear to be influential factors in osteophyte formation [14]. Mesenchymal stem cells of the synovium or periostium are likely precursors, with synovial macrophages and a milieu of growth factors and extracellular matrix molecules acting as probable mediators in this process [29].

\section{Clinical presentation}

Pain within the axial spine at the site of these degenerate changes is not surprising as nociceptive pain generators have been identified within facet joints, intervertebral disks, sacroiliac joints, nerve root dura, and myofascial structures within the axial spine [9].

These degenerative anatomical changes may culminate in a clinical presentation of spinal stenosis, or narrowing within the spinal canal [30] through progressive ingrowth of osteophytes, hypertrophy of the inferior articular process [31], disk herniation, bulging of the ligamentum flavum [17], or spondylolisthesis. The clinical result: a constellation of pain symptoms encompassed in the term neurogenic claudication (NC). NC may include (to varying extents) lower back pain, leg pain, as well as numbness and motor weakness to lower extremities that worsen with upright stance and walking, and improve with sitting and supine positioning [30].

Clinical presentations of radiculopathy may emanate from many sources, all of which can be explained by the degenerative process. Disk bulging may affect descending rootlets of the cauda equina, nerve roots exiting at the next lower intervertebral canal, or the spinal nerve within its ventral ramus, if protruding centrally, posterolaterally, or laterally, respectively [32]. Osteophyte lipping along the posterior aspect of vertebral bodies, along upper or lower margins, may similarly impinge upon the same neural structures as the bulging disk just described [17, 33]. Hypertrophic changes to the superior articular process may intrude upon nerve roots within the upper nerve root canal, dural sac, or prior to exiting from next lower intervertebral canal, depending on their projection [34]. These theoretical forms of impingement have been substantiated through cadaver studies. A $70 \%$ reduction or $30 \%$ residual diameter of neuroforminal space is cited as the critical amount of occlusion to induce neural compromise [15]. Moreover, compression of the posterior disk to less than $4 \mathrm{~mm}$ height, or foraminal height to less than $15 \mathrm{~mm}$ has also been 
determined as critical dimensions for foraminal stenosis and nerve impingement [35].

\section{Etiology/risk factors}

What factors mediate this degenerative progression? What leads a large portion of the population to manifest spondylosis, even early on in their lives? Given the substantial variability in the number and degree of spine changes observed in individuals and the wide range of clinical presentations, answers to these questions hold promise to broaden treatment options.

The influence of age

Large studies of osteoarthritis have long recognized the aging process to be the strongest risk factor for bony degeneration, particularly within the spine [36]. An extensive autopsy study in 1926 reported evidence of spondylitis deformans to increase in a linear fashion from $0 \%$ to $72 \%$ between the ages of 39 and 70 years [37]. A subsequent autopsy study by Miller et al. [38] similarly noted an increase in disk degeneration from $16 \%$ at age 20 to about $98 \%$ at age 70 years based on macroscopic disk degeneration grades of 600 specimens. Other studies corroborate this finding $[20,39]$.

The associations are nevertheless imperfect. Kramer [40] found increasing age to be significantly associated with osteophyte formation but not predictive of the degree of disk space narrowing observed in a retrospective review of radiographs of women. She observed significant variability, noting "although few younger women have high average scores, some older women have no radiographic sign of OA, while others are severely affected." Multiple studies have also demonstrated the presence of significant lumbar degeneration to be evident even within the first two decades $[38,39]$. Such variability within members of the same age category suggests the influence of other contributing factors.

The impact of activity and occupation

Disk generation has long been associated with certain activities. Retrospective studies cite Body Mass Index (BMI), incident back trauma, daily spine loading (twisting, lifting, bending, and sustained nonneutral postures), and whole body vibration (such as vehicular driving) to be factors which increase both the likelihood and severity of spondylosis [20, 41]. While these correlations exist, a study following progressive radiographic changes in lumber DDD did not find significant associations with the extent of physical activity, noting only age, back pain, and associated hip OA to be predictive of DDD and osteophyte changes [42].
The role of heredity

Genetic factors likely influence the formation of osteophytes and disk degeneration. Spector and MacGregor [43] proposed that $50 \%$ of the variability found in osteoarthritis can be attributed to heritable factors. Similarly, twin studies evaluating the progression of degenerative changes in lumbar MRI imaging suggest that approximately half (47-66\%) of the variance could be explained by genetic and environmental factors, attributing only $2-10 \%$ of variance to physical loading and resistance training [44]. Another twin study revealed a high degree of similarity in signal intensity, disk height narrowing, disk bulging, and end-plate changes [45]. A search for these underlying genetic factors has identified polymorphisms in genes regulating inflammatory pathways and a Vitamin D Receptor allele to correspond to radiographic progression of lumbar disk degeneration [46].

A functional adaptation?

Is osteophyte formation inherently pathological? van der Kraan and van den Berg question if osteophyte formation may represent a remodeling process, functionally adapting to the instability or the changes in the demands of the spine [14]. Likewise, Humzah and Soames [47] emphasize the dynamic and reparative qualities of the intervertebral disk, responding to variations in mechanical loading and influencing vertebral kinematics to extend this argument. Osteophytes may form in the absence of other degenerative processes, and cartilaginous damage may exist without corresponding osteophytes [14]. Although there remains a strong association between the presence of osteophytes and other degenerative spine changes, isolated instances of one without the other occur, in the absence of overt symptoms.

\section{A diagnostic approach}

The initial evaluation for patients with low back pain begins with an accurate history and thorough physical exam with appropriate provocative testing. These first steps are complicated by the subjectivity of patient experiences of chronic spinal pain and the inherent difficulty isolating the anatomic region of interest during provocative testing without the influence of neighboring structures.

Radiographic studies, whether plain film, CT, CT myelogram, or MRI, may provide useful confirmatory evidence to support an exam finding and localize a degenerative lesion or area of nerve compression. However, imaging is an imperfect science, identifying the underlying cause of LBP in only $15 \%$ of patients in the absence of clear disk herniation or neurological deficit [25]. 
Furthermore, there remains a frequent disconnection between the symptom severity and the degree of anatomical or radiographic changes [18]. While correlations between the number and severity of osteophytes and back pain exist $[20,22]$, the prevalence of degenerative changes among asymptomatic patients underlies the difficulty assigning clinical relevance to observed radiographic changes in patients with LBP.

Nerve compression symptoms by clinical history may also be confirmed by electromyographic studies demonstrating normal distal motor and sensory nerve conduction studies with abnormal needle exam. Diagnostic injections can facilitate localization by isolating and anesthetizing irritated nerve roots (via epidural), or by blocking suspected pain generators within facet joints, sacroiliac joints, or the disk space itself (via discography) [48].

\section{Intervention and treatment options}

Given our limited ability to isolate causative sources of chronic lower back pain, there is a little consensus with regard to a definitive treatment approach. Substantial variation in management by conservative and invasive approaches exists between practitioners throughout the country [8]. We will briefly describe these treatment options for the management of chronic low back pain syndromes within each of the four primary categories: physical therapy (and associated modalities and behavioral techniques), pharmacotherapy, injection therapy, and surgical intervention.

\section{Exercise-based and behavioral interventions}

\section{Exercise therapy}

Exercise therapy (ET) remains one of the conservative mainstays of treatment for chronic lumbar spine pain, and may be tailored to include aerobic exercise, muscle strengthening, and stretching exercises [49]. Significant variation in regimen, intensity, and frequency of prescribed programs presents challenges to assessing efficacy among patients [50]. One meta-analysis of the current literature exploring the role of ET in patients with varying duration of symptoms found a graded exercise program implemented within the occupational setting demonstrated some effectiveness in subacute LBP. Among those suffering chronic pain symptoms, small, but statistically significant improvements were observed among patients, with regard to pain reduction and functional improvement [49]. The optimal approach to exercise therapy in chronic low back pain sufferers appears to be those regimens involving an individually-designed exercise program emphasizing stretching and muscle strengthening, administered in a supervised fashion, with high frequency and close adherence. Such results are complemented by other conservative approaches, including NSAIDS, manual therapies, and daily physical activity [50].

\section{Transcutaneous electrical nerve stimulation (TENS)}

A "TENS" unit is a therapeutic modality involving skin surface electrodes which deliver electrical stimulation to peripheral nerves in an effort to relieve pain noninvasively. Such devices are frequently available in outpatient exercise therapy settings, with up to a third of patients experiencing mild skin irritation following treatment [51]. While one small study identified an immediate reduction in pain symptoms $1 \mathrm{~h}$ following TENS application, there remains little evidence of long-term relief. Another larger study did not discover significant improvement with TENS compared with placebo with regard to pain, functional status, or range of motion [52, 53].

\section{Back school}

Back School was introduced first in Sweden with the purpose of minimizing lower back pain symptoms and their reoccurrence through review with patients of lumbar anatomy, concepts of posture, ergonomics, and appropriate back exercises [54]. Two meta-analyses concluded that there is moderate evidence for improvement in both pain and functional status for chronic low back pain within short and intermediate time courses, when measured against other modalities such as exercise, joint manipulation, myofascial therapy, and/or other educational therapy [52, 54].

\section{Lumbar supports}

Lumbar back supports may provide benefit to patients suffering chronic LBP secondary to degenerative processes through several potential, debated mechanisms. Supports are designed to limit spine motion, stabilize, correct deformity, and reduce mechanical forces. They may further have effects by massaging painful areas and applying beneficial heat; however, they may also function as a placebo. There is moderate available evidence evaluating efficacy of lumbar supports within a mixed population of acute, subacute, and chronic LBP sufferers to suggest that lumbar supports are not more effective than other treatment forms; data is conflicting with regard to patient improvement and functional ability to return to work [52].

\section{Traction}

Lumbar traction applies a longitudinal force to the axial spine through use of a harness attached to the iliac crest and 
lower rib cage to relieve chronic low back pain. The forces, which open intervertebral space and decrease spine lordosis, are adjusted both with regard to level and duration and may closely be measured in motorized and bed rest devices. Temporary spine realignments are theorized to improve symptoms related to degenerative spine disease by relieving mechanical stress, nerve compression, and adhesions of the facet and annulus, as well as through disruption of nociceptive pain signals [52]. Nonetheless, patients with chronic symptoms and radicular pain have not found traction to provide significant improvement in pain nor daily functioning [55-57]. Little is known with regard to the risks associated with the applied forces. Isolated case reports cite nerve impingement with heavy forces, and the potential for respiratory constraints or blood pressure changes due to the harness placement and positioning [52].

\section{Spine manipulation}

Spine manipulation is a manual therapy approach involving low-velocity, long lever manipulation of a joint beyond the accustomed, but not anatomical range of motion. The precise mechanism for improvement in low back pain sufferers remains unclear. Manipulative therapy may function through: "(1) release for the entrapped synovial folds, (2) relaxation of hypertonic muscle, (3) disruption of articular or periarticular adhesion, (4) unbuckling of motion segments that have undergone disproportionate displacement, (5) reduction of disk bulge, (6) repositioning of miniscule structures within the articular surface, (7) mechanical stimulation of nociceptive joint fibers, (8) change in neurophysiological function, and (9) reduction of muscle spasm" [58].

Available research regarding its efficacy in the context of chronic LBP finds spinal manipulation to be "more effective" compared to sham manipulation with regard to both short- and long-term relief of pain, as well as shortterm functional improvement [52]. Compared with other conventional, conservative treatment approaches such as exercise therapy, back school, and NSAID prescription, spinal manipulation appears comparable in its effectiveness both in short- and long-term benefits [52, 59]. Research exploring the safety of such therapy among trained therapists found a very low risk of complications, with clinically worsened disk herniation or cauda equina syndrome occurring in fewer than 1/3.7 million [60].

\section{Massage therapy}

Massage therapy for chronic LBP appears to provide some beneficial relief. Weighed against other interventions, it proved less efficacious than TENS and manipulation, comparable with corsets and exercise regimens, and superior to acupuncture and other relaxation therapies, when followed over a 1-year course. Such preliminary results need confirmation, and evaluation for cost-effectiveness, but nevertheless suggest a potential role in certain, interested patients [61].

\section{Multidisciplinary back therapy: the bio-psychosocial approach}

Psychopathology is well recognized for its association with chronic spinal pain, and, when untreated, its ability to compromise management efforts [25]. For this reason, patients may find relief through learned cognitive strategies, termed "behavioral", or "bio-psychosocial" therapy. Strategies involving reinforcement, modified expectations, imagery/relaxation techniques, and learned control of physiological responses aim to reduce a patient's perception of disability and pain symptoms. To date, evidence is limited with regard to the efficacy of operant, cognitive, and respondent treatment approaches [52].

\section{Pharmacotherapy}

Treatment efforts to control pain and swelling, minimize disability, and improve the quality of life with lumbar spondylosis often require medication to complement nonpharmacologic interventions. Extensive research efforts have explored the efficacy of different oral medications in the management of low back pain secondary to degenerative processes. Nonetheless, there remains no clear consensus regarding the gold-standard approach to pharmacologic management [62].

\section{NSAIDS}

NSAIDS are widely regarded as an appropriate first step in management, providing analgesic and anti-inflammatory effects. There is adequate data demonstrating efficacy in pain reduction in the context of chronic low back pain [6366], with use most commonly limited by gastrointestinal (GI) complaints. COX2 inhibitors offer modest relief in chronic LBP and improved function in the long-term setting. While they elicit fewer GI complications, their utilization has been curbed due to evidence for increased cardiovascular risk with prolonged use [52].

\section{Opioid medications}

Opioid medications may be considered as an alternative or augmentive therapy for patients suffering from gastrointestinal effects or poor pain control on NSAID management. The practice of prescribing narcotics for chronic low back pain sufferers is extremely variable within practitioners, with 
a range of 3-66\% of chronic LBP patients taking some form of opioid in various literature studies [67]. These patients tend to report greater distress/suffering and higher functional disability scores [68, 69]. Two meta-analyses suggest a modest short-term benefit of opioid use for treatment of chronic LBP while issuing a warning regarding the limited quality of available studies and the high rate of tolerance and abuse associated with long-term narcotic use within this patient population $[62,67]$.

\section{Antidepressants}

The use of antidepressants for treatment of LBP symptoms has also been explored considerably given their proposed analgesic value at low doses, and dual role in treatment of commonly comorbid depression that accompanies LBP and may negatively impact both sleep and pain tolerance [52]. Two separate reviews of available literature found evidence for pain relief with antidepressants, but no significant impact on functioning [70, 71].

\section{Muscle relaxants}

Muscle relaxants, taking the form of either antispasmodic or antispasticity medications, may provide benefit in chronic low back pain attributed to degenerative conditions. There remains moderate to strong evidence through several trials comparing either a benzodiazepine, or nonbenzodiazepine with placebo that muscle relaxants provide benefit with regard to short-term pain relief and overall functioning [52, 62, 72].

\section{Injection therapy}

\section{Epidural steroid injections}

Epidural steroid injections (ESI) have become a common interventional strategy in the management of chronic axial and radicular pain due to degeneration of the lumbar spine. These injections may be performed through interlaminar, transforaminal, or caudal approaches. Usually by way of needles guided under fluoroscopy, contrast, then local anesthetic and steroid are infused into the epidural space at the target vertebral level and bathe exiting nerve roots. Symptomatic relief is theorized to occur through complementary mechanisms. Local anesthetics provide quick diagnostic confirmation, and therapeutically may short circuit the "pain spasm cycle" and block pain signal transmission [73]. Corticosteroids are well recognized for their capacity to reduce inflammation through blockade of pro-inflammatory mediators.

Within the span of less than one decade (1998-2005), the number of ESI procedures performed has increased by
$121 \%$ [73]. Despite this widespread utilization, controversy remains regarding the efficacy of these injections, fueled by the expense and the infrequent but potential risks related to needle placement and adverse medication reactions. Available published data cites wide ranges in reported success rates due to variation in study designs, distinct procedural techniques, small cohorts, and imperfect control groups [74]. For example, prior to the year 2000, few efficacy studies of lumbar ESI utilized fluoroscopy to establish appropriate needle position. Research suggests that without fluoroscopic guidance confirmation, needle position may be inappropriate in as frequently as $25 \%$ of cases, even with experienced providers [75]. Review articles and practicing clinicians alike must interpret such methodological differences between studies to assemble opinions on efficacy and utility of ESI for LBP treatment.

One such review exploring efficacy of interlaminar lumbar injections concluded strong evidence for short-term pain relief and limited benefit for long-term benefit [73] citing, among many, randomized controlled trials (RCT) by Arden and Carette of unilateral sciatic pain, finding statistically significant improvement in up to $75 \%$ of patients with steroid/anesthesia versus saline injections at 3 weeks, with benefit waning by 6 weeks and 3 months, respectively [76, 77].

The same review evaluating the transforaminal injection approach to unilateral sciatica found strong evidence for short-term, and moderate evidence for long-term symptom and functional improvement, based on the findings from several RCT. Vad et al. [78] studied 48 patients with herniated nucleus pulposus or radicular pain, treated with transforaminal ESI versus trigger point injections, citing an $84 \%$ improvement in functional scoring compared with $48 \%$ in the control group, extending for a follow-up period of 1 year. Lutz et al. [79] treated and followed a different cohort of 69 patients with the same underlying diagnoses, with transforaminal ESI for 80 weeks demonstrating $75 \%$ of patients with a successful long-term outcome, defined as $>50 \%$ reduction in pain scores. In spinal stenosis, transforaminal ESI has achieved $>50 \%$ pain reduction, improved walking, and improved standing tolerance in symptomatic patients extending through 1 year follow-up [80]. Furthermore, prospective trials by Yang and Riew found patients with severe lumbar radiculopathies and spinal stenosis treated with transforaminal injections experienced such sustained functional and symptomatic benefits so as to avoid intended surgical intervention [8183].

\section{Facet injections}

Facet joints, also termed zygapophysial joints, are paired diarthrodial articulations between adjacent vertebrae. 
These joints are innervated from the medial branches of the dorsal rami and, through anatomical studies, possess free and encapsulated nerve endings, mechanoreceptors, and nociceptors. Inflammation to the joint creates pain signals which are implicated in $15-45 \%$ of patients with low back pain [25].

Diagnostic blocks of the joint inject anesthesia directly into the joint space or associated medial branch (MBB). Systematic reviews of both retrospective and prospective trials reveal single diagnostic facet blocks carry a falsepositive rate of $22 \%$ to $47 \%$ [84] and medial branch blocks of $17-47 \%$ in the lumbar spine [85].

Subsequent therapeutic injections are similarly performed through either approach, with systematic reviews concluding moderate evidence available for short-term and long-term pain relief with facet blocks [86]. This evidence stems from studies such as Fuch's RCT showing significant pain relief, functional improvement, and quality of life enhancement at 3 and 6 month intervals [87]. By contrast, Carette et al. [88] found no meaningful difference in perceived benefit between patients treated with steroid versus saline (control) injection at 3 and 6 month intervals. Available literature of MBB similarly show moderate evidence for short- and long-term relief [86] based on RCT of MBB under fluoroscopy, showing significant relief (by means of pain relief, physical health, psychological benefit, reduced narcotic intake, and employment status), with 1-3 injections in $100 \%$ patients at 3 months, $75-88 \%$ at 6 months, and $17-25 \%$ at 1 year [89].

\section{SI joint injections}

The sacroiliac joint space is a diarthrodial synovial joint with debated innervation patterns that involve both myelinated and unmyelinated axons. Injury or inflammation at the joint creates pain signals which are implicated in 10 $27 \%$ of patients with low back pain [25] and may also refer to the buttocks, groin, thigh, and lower extremities.

There is moderate evidence to support the use of both diagnostic and therapeutic blocks of the SI joint [25]. Pereira treated 10 patients with MRI-guided bilateral SI joint injections of steroid, eight of whom reported "good to excellent" pain relief persisting through 13 months followup [90]. Maugers compared corticosteroid versus placebo injections under fluoroscopic guidance in SI joints of 10 symptomatic patients, reporting patient benefit only in the corticosteroid group. That benefit waned slowly over time, from $70 \%$ of patients at 1 month, to $62 \%$ at 3 months, and $58 \%$ at 6 months [91]. At this point, there is limited evidence to support radiofrequency neurotomy (ablation procedure) of the SI joint [92].

A recent meta-analysis provided the following guiding principles with regard to the frequency these procedures should be implemented in clinical practice. In cases of ESI, facet, and sacroiliac injections, diagnostic injections should be considered at intervals of no sooner than 1-2 weeks apart. Therapeutic injections may be performed at most every $2-3$ months, provided the patient experiences greater than $50 \%$ relief within 6 weeks. Injections should be performed only as they are medically necessary given their associated risks and significant costs [25].

Intradiscal nonoperative therapies for discogenic pain

Discogenic pain has been identified as the source in $39 \%$ of patients with chronic low back pain. As described above, a cascade of effects induces the changes in the disk which generate pain. Discography seeks, when noninvasive imaging has failed, to identify damaged disks through injection of fluid into disk levels, in an attempt to reproduce patient symptoms. The technique's utility remains controversial given significant potential for false positives. Provoked pain may be alternatively represent central hyperalgesia, reflect the patient's chronic pain or psychological state, or result from technical difficulty due to the procedure itself [93].

If a diseased disk is identified, several treatment options exist. In addition to surgical correction, there are minimally invasive options. Both Intradiscal electrothermal therapy (IDET) and Radiofrequency posterior annuloplasty (RPA) involve electrode placement into the disk. Heat and electrical current coagulate the posterior anulus, and in doing so, strengthen collagen fibers, seal figures, denature inflammatory exudates, and coagulate nociceptors [25]. Current evidence provides moderate support for IDET in discogenic pain sufferers. Preliminary studies of RPA provide limited support for short term relief, with indeterminate long-term value. Both procedures have associated complications, including catheter malfunction, nerve root injuries, postprocedure disk herniation, and infection risk [25].

\section{Surgical options}

Surgical interventions are generally reserved for patients who have failed conservative options. Patients must be considered as appropriate "surgical candidates," taking into consideration medical comorbidities as well as age, socioeconomic status, and projected activity level following a procedure [18]. Many surgical approaches have been developed to achieve one of the two primary goals: spinal fusion or spine decompression (or both).

Spinal fusion is considered in patients with malalignment or excessive motion of the spine, as seen with DDD and spondylolisthesis. Several surgical fusion approaches exist, all involving the addition of a bone graft to grow between vertebral elements to limit associated motion. Decompression surgery is indicated for patients with clear 


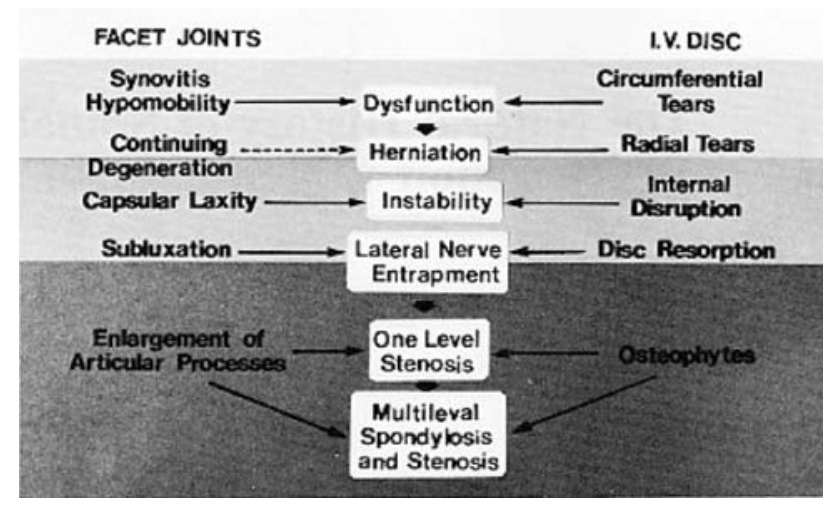

Fig. 1 The spectrum of pathological changes in facial joints and the disk and the interaction of these changes. The upper light horizontal bar represents dysfunction, the middle darker bar instability, and the lower dark bar stabilization

evidence of neural impingement, correcting the intrusion of bone or disk as might be seen in spinal or foraminal stenosis, disk herniation, osteophytosis, or degenerative spondylolisthesis. Despite dramatic increases in the number of procedures performed over the last several decades, there remains controversy as to the efficacy of these procedures in resolving chronic low back unresponsive to conservative management.

Controversy arises, in part, due to the inherent challenges of comparing the available research. Systematic reviews cite the heterogeneity of current trials which evaluate different surgical techniques with differing comparison groups and limited follow-up, frequently without patient-centered or pain outcomes included [18]. Some case series reveal promising results [94]. Nonetheless, a recent meta-analysis of 31 randomized controlled trials, concluded, "[there is] no clear evidence about the most effective technique of decompression for spinal stenosis or the extent of that decompression. There is limited evidence that adjunct fusion to supplement decompression for degenerative spondylolisthesis produces less progressive slip and better clinical outcomes than decompression alone." Another review, noting no statistically significant improvement in patients undergoing fusion compared with nonsurgical interventions commented, "surgeons should recommend spinal fusion cautiously to patients with chronic low back pain. Further long-term follow-ups of the studies reviewed in this metaanalysis are required to provide more conclusive evidence in favor of either treatment" [95].

\section{Conclusion}

Lumbar spondylosis is a complicated diagnosis. We chose to define it broadly as degenerative conditions of the spine, but definitions vary widely within the literature. While it may not present a challenge to identify radiographically, its pervasiveness throughout all patient populations makes the exact diagnosis of symptomatic cases extremely difficult. Moreover, there is no current concrete, gold-standard treatment approach to the diverse range of patient presentations despite substantial research efforts to identify conservative and more invasive methods of managing symptoms and slowing progressive decline. Given the morbidity of low back pain within the population and its social and economic implications, this area will continue to be a critical research focus. Important clues are in place, from genetic studies, risk factor analysis, and explorative treatment approaches. These efforts, and future endeavors will no doubt fine-tune and present means to tackle not only symptoms, but confront progression, and ultimately prevention of disease in years to come.

Open Access This article is distributed under the terms of the Creative Commons Attribution Noncommercial License which permits any noncommercial use, distribution, and reproduction in any medium, provided the original author(s) and source are credited.

\section{References}

1. Frymoyer JW. Back pain and sciatica. N Engl J Med. 1988; 318:291-300.

2. van Geen J, Edelaar M, Janssen M, et al. The long-term effect of multidisciplinary back training: a systematic review. Spine. 2007;32(2):249-55.

3. Andersson GB. Epidemiological features of chronic low pain. Lancet. 1999;354:581-5.

4. Dillane J, Fry J, Kalton G. Acute back syndrome-a study from general practice. Br Med J. 1966;2:82-4.

5. Andersson HI, Ejlertsson G, Leden I, et al. Chronic pain in a geographically defined general population: studies of differences in age, gender, social class and pain localization. Clin J Pain. 1993;9:174-82.

6. Andersson GB. The epidemiology of spinal disorders. In: Frymoyer JW, editor. The adult spine: principles and practice. 2nd ed. Philadelphia, PA: Lippincott-Raven; 1997.

7. van Tulder MW, Koes BW, Bouter LM. A cost-of-illness study of back pain in The Netherlands. Pain. 1995;62:233-40.

8. Deyo R, Cherkin D, Conrad D. Cost, controversy, crisis: low back pain and the health of the public. Annu Rev Publ Health. 1991; $12: 141-56$.

9. Bogduk N. The innervation of the lumbar spine. Spine. 1983;8:286-93.

10. Williams ME, Hadler NM. The illness as the focus of geriatric medicine. N Engl J Med. 1983;308:1357-60.

11. Boden SD, Davis DO, Dina TS, et al. Abnormal magnetic-resonance scans of the lumbar spine in asymptomatic subjects: a prospective investigation. J Bone Joint Surg. 1990;72:403-8.

12. Wiesel SW, Tsourmas N, Feffer HL, et al. A study of computerassisted tomography. The incidence of positive CAT scans in an asymptomatic group of patients. Spine. 1984;9:549.

13. Pye SR, Reid DM, Lunt M, et al. Lumbar disc degeneration: association between osteophytes, end-plate sclerosis and disc space narrowing. Ann Rheum Dis. 2007;66(3):330-3.

14. van der Kraan PM, van den Berg WB. Osteophytes: relevance and biology. Osteoarthritis cartilage. 2007;15(3):237-44. 
15. Rothschild B. Lumbar spondylosis. In: Emedicine publication. 2008. Available via WebMD. http://emedicine.medscape.com/ article/249036-overview.

16. Fardon DF, Milette PC. Nomenclature and classification of lumbar disc pathology. Spine. 2001;26(5):E93-113.

17. Schneck CD. The anatomy of lumbar spondylosis. Clin Orthop Relat Res. 1985;193:20-36.

18. Gibson JNA, Waddell G. Surgery for degenerative lumbar spondylosis. Spine. 2005;20:2312-20.

19. Symmons DPM, van Hemert AM, Vandenbrouke JP, et al. A longitudinal study of back pain and radiological changes in the lumbar spines of middle aged women: radiographic findings. Ann Rheum Dis. 1991;50:162-6.

20. O'Neill TW, McCloskey EV, Kanis JA, et al. The distribution, determinants, and clinical correlates of vertebral osteophytosis: a population based survey. J Rheumatol. 1999;26:842-8.

21. Jensen MC, Brant-Zawadzki MN, Obuchowski N, et al. Magnetic resonance imaging of the lumbar spine in people without back pain. N Engl J Med. 1994;331(2):69-73.

22. Frymoyer JW, Newberg A, Pope MH, et al. Spine radiographs in patients with low-back pain. An epidemiological study in men. $\mathbf{J}$ Bone Joint Surg Am. 1984;66(7):1048-55.

23. Lawrence JS. Disc degeneration. Its frequency and relationship to symptoms. Ann Rheum Dis. 1969;28:121-38.

24. Kirkaldy-Willis W, Bernard T. Managing low back pain. New York: Churchill livingstone; 1983.

25. Boswell MV, Trescot AM, Datta S, et al. Interventional techniques: evidence-based practice guidelines in the management of chronic spinal pain. Pain Physician. 2007;10(1):7-111.

26. Kirkaldy-Willis WH, Wedge JH, Yong-Hing K, et al. Pathology and pathogenesis of lumbar spondylosis and stenosis. Spine. 1978;3:319-28.

27. Menkes CJ, Lane NE. Are osteophytes good or bad? Osteoarthritis Cartilage. 2004;12(Suppl A):S53-4.

28. Peng B, Hou S, Shi Q, et al. Experimental study on mechanism of vertebral osteophyte formation. Chin J Traumatol. 2000;3(4):202-5.

29. Blom AB, van Lent PL, Holfhuysen AE, et al. Synovial lining macrophages mediate osteophyte formation during experimental osteoarthritis. Osteoarthritis Cartilage. 2004;12(8):627-35.

30. Snyder DL, Doggett D, Turkelson C. Treatment of degenerative lumbar spinal stenosis. Am Fam Physician. 2004;70(3):517-20.

31. Sheldon JT, Sersland T, Leborgne J. Computed tomography of the lower lumbar vertebral column. Radiology. 1977;124:113.

32. Williams AL, Haughton VM, Daniels DL, Thornton RS. CT recognition of lateral lumbar disc herniation. Am J Roentgenol. 1982;139(1):345-7.

33. Matsumoto M, Chiba K, Nojiri K, Ishikawa M, Toyama Y, Nishikawa Y. Extraforaminal entrapment of the fifth lumbar spinal nerve by osteophytes of the lumbosacral spine: anatomic study and a report of four cases. Spine. 2002;27(6):E169-73. Mar 15.

34. MacNab I. Backache. Baltimore: Williams \& Wilkins; 1977.

35. Hasegawa T, An HS, Haughton VM, et al. Lumbar foraminal stenosis: critical heights of the intervertebral discs and foramina. A cryomicrotome study in cadavera. J Bone Joint Surg Am. 1995;77(1):32-8.

36. Buckwalter JA, Saltzman C, Brown T. The impact of osteoarthritis: implications for research. Clin Orthop Relat Res. 2004;427:S6-15.

37. Heine J, Ûber die. Arthritis deformans. Virchows Arch Pathol Anat. 1926;260:521-663.

38. Miller JA, Schmatz C, Schultz AB. Lumbar disc degeneration: correlation with age, sex, and spine level in 600 autopsy specimens. Spine. 1988;13:173-8.

39. Boos N, Weissbach S, Rohrbach $\mathrm{H}$, et al. Classification of agerelated changes in lumbar intervertebral discs: 2002 Volvo Award in basic science. Spine. 2002;27:2631-44.
40. Kramer PA. Prevalence and distribution of spinal osteoarthritis in women. Spine. 2006;31(24):2843-8.

41. Videman T, Battié MC. Spine update: the influence of occupation on lumbar degeneration. Spine. 1999;24:1164-8.

42. Hassett G, Hart DJ, Manek NJ, et al. Risk factors for progression of lumbar spine disc degeneration: the Chingford Study. Arthritis Rheum. 2003;48(11):3112-7.

43. Spector TD, MacGregor AJ. Risk factors for osteoarthritis: genetics. Osteoarthritis Cartilage. 2004;12(Suppl A):S39-44.

44. Videman T, Battié MC, Ripatti S, et al. Determinants of the progression in lumbar degeneration: a 5-year follow-up study of adult male monozygotic twins. Spine. 2006;31(6):671-8.

45. Battié MC, Videman T, Gibbons L, et al. Determinants of lumbar disc degeneration: a study relating lifetime exposures and MRI findings in identical twins. Spine. 1995;20:2601-12.

46. Videman T, Leppavuori J, Kaprio J, et al. Intragenic polymorphisms of the vitamin $\mathrm{D}$ receptor gene associated with intervertebral disc degeneration. Spine. 1998;23:2477-85.

47. Humzah MD, Soames RW. Human intervertebral disc: structure and function [Review]. Anat Rec. 1988;220:337-56.

48. Lamer TJ. Lumbar spine pain originating from vertebral osteophytes. Reg Anesth Pain Med. 1999;24(4):347-51.

49. Hayden JA, van Tulder MW, Malmivaara AV, et al. Meta-analysis: exercise therapy for nonspecific low back pain. Ann Intern Med. 2005;142:765-75.

50. Hayden JA, van Tulder MW, Tomlinson G. Systematic review: strategies for using exercise therapy to improve outcomes in chronic low back pain. Ann Intern Med. 2005;142:776-85.

51. Deyo RA, Walsh NE, Martin DC, et al. A controlled trial of transcutaneous electrical nerve stimulation (TENS) and exercise for chronic low back pain. N Engl J Med. 1990;322:1627-34.

52. Van Tulder MW, Koes B, Malmivaara. Outcome of non-invasive treatment modalities on back pain: an evidence-based review. Eur Spine J. 2006;15(1):S64-81.

53. Milne S, Welch V, Brosseau L. Transcutaneous electrical nerve stimulation (TENS) for chronic low back pain, vol. 4. Oxford: The Cochrane Library; 2004.

54. Heymans MW, van Tulder MW, Esmail R, et al. Back schools for nonspecific low back pain: a systematic review within the framework of the cochrane collaboration back review group. Spine. 2005;30(19):2153-63.

55. Van der Heijden GJMG, Beurskens AJHM, Dirx MJM, et al. Efficacy of lumbar traction: a randomized clinical trial. Physiotherapy. 1995;81:29-35.

56. Borman P, Keskin D, Bodur H. The efficacy of lumbar traction in the management of patients with low back pain. Rheumatol Int. 2003;23:82-6.

57. Werners R, Pynsent PB, Bulstrode CJK. Randomized trial comparing interferential therapy with motorized lumbar traction and massage in the management of low back pain in a primary care setting. Spine. 1999;24:1579-84.

58. Assendelft WJ, Morton SC, Yu EI, et al. Spinal manipulative therapy for low back pain. A meta-analysis of effectiveness relative to other therapies. Ann Intern Med. 2003;138:871-81.

59. Bromfort G, Haas M, Evans RL, et al. Efficacy of spinal manipulation and mobilization for low back pain and neck pain: a systematic review and best evidence synthesis. Spine. 2004;4(3):335-56.

60. Oliphant D. Safety of spinal manipulation in the treatment of lumbar disk herniations: a systematic review and risk assessment. J Manipulative Physiol Ther. 2004;27:197-210.

61. Furlan AD, Brosseau L, Imamura M, et al. Massage for low-back pain: a systematic review within the framework of the Cochrane Collaboration Back Review Group. Spine. 2002;27(17):1896-910.

62. Schnitzer TJ, Ferraro A, Hunsche E, et al. A comprehensive review of clinical trials on the efficacy and safety of drugs for the 
treatment of low back pain. J Pain Symptom Manage. 2004;28: 72-95.

63. Hickey RF. Chronic low back pain: a comparison of diflunisal with paracetamol. N Z Med J. 1982;95(707):312-4.

64. Videman T, Osterman K. Double-blind parallel study of piroxicam versus indomethacin in the treatment of low back pain. Ann Clin Res. 1984;16:156-60.

65. Berry H, Bloom B, Hamilton EB, et al. Naproxen sodium, diflunisal, and placebo in the treatment of chronic back pain. Ann Rheum Dis. 1982;41(2):129-32.

66. DeMoor M, Ooghe R. Clinical trial of oxametacin in low back pain and cervicobrachialgia. Ars Medici Revue Internationale De Therapie Pratique. 1982;37:1509-15.

67. Martell BA, O'Connor PG, Kerns RD, et al. Systematic review: opioid treatment for chronic back pain: prevalence, efficacy, and association with addition. Ann Intern Med. 2007;146(2):116-27.

68. Fillingim RB, Doleys DM, Edwards RR, et al. Clinical characteristics of chronic back pain as a function of gender and oral opioid use. Spine. 2003;28:143-50.

69. Turk DC, Okifuji A. What factors affect physicians' decisions to prescribe opioids for chronic noncancer pain patients? Clin J Pain. 1997;13:330-6.

70. Salerno SM, Browning R, Jackson JL. The effect of antidepressant treatment in chronic back pain: a meta-analysis. Arch Intern Med. 2002;162:19-24.

71. Staiger O, Barak G, Sullivan MD, Deyo RA. Systematic review of antidepressants in the treatment of chronic low back pain. Spine. 2003;28:2540-5.

72. Salzmann E, Pforringer W, Paal G, et al. Treatment of chronic low-back syndrome with tetrazepam in a placebo controlled double-blind trial. J Drug Dev. 1992;4:219-28.

73. Abdi S, Datta S, Trescot AM, et al. Epidural steroids in the management of chronic spinal pain: a systematic review. Pain Physician. 2007;10:185-212.

74. Koes BW, Scholten RJ, Mens JM, et al. Efficacy of epidural steroid injections for low-back pain and sciatica: a systematic review of randomized clinical trials. Pain. 1995;63(3):279-88.

75. Stitz MY, Sommer HM. Accuracy of blind versus fluoroscopically guided caudal epidural injection. Spine. 1999;24(13):1371-6.

76. Arden NK, Price C, Reading I, et al. A multicentre randomized controlled trial of epidural corticosteroid injections for sciatica: the WEST study. Rheumatology. 2005;44:1399-406.

77. Carette S, Leclaire R, Marcoux S, et al. Epidural corticosteroid injections for sciatica due to herniated nucleus pulposus. N Engl J Med. 1997;336:1634-40.

78. Vad VB, Bhat AL, Lutz GE, et al. Transforaminal epidural steroid injections in lumbosacral radiculopathy: a prospective randomized study. Spine. 2002;27:11-6.

79. Lutz GE, Vad VB, Wisneski RJ. Fluoroscopic transforaminal lumbar epidural steroids: an outcome study. Arch Phys Med Rehabil. 1998;79:1362-6.
80. Botwin KP, Gruber RD, Bouchlas CG, et al. Fluoroscopically guided lumbar transforaminal epidural steroid injections in degenerative lumbar stenosis: an outcome study. Am J Phys Med Rehabil. 2002;81:898-905.

81. Riew KD, Park JB, Cho YS, et al. Nerve root blocks in the treatment of lumbar radicular pain: a minimum 5-year follow up. J Bone Joint Surg Am. 2006;88:1722-5.

82. Riew KD, Yin Y, Gilula L, Bridwell, et al. The effect of nerveroot injections on the need for operative treatment of lumbar radicular pain. J Bone Joint Surg Am. 2000;82:1589-93.

83. Yang SC, Fu TS, Lai PL, et al. Transforaminal epidural steroid injection for discectomy candidates: an outcome study with a minimum of 2 year follow-up. Chang Gung Med J. 2006;29:93-9.

84. Boswell MV, Singh V, Staats PS, et al. Accuracy of precision diagnostic blocks in the diagnosis of chronic spinal pain of facet or zygapophysial joint origin: a systematic review. Pain Physician. 2003;6:449-56.

85. Sehgal N, Dunbar EE, Shah RV, et al. Systematic review of diagnostic utility of facet (zygapophysial) joint injections in chronic spinal pain: an update. Pain Physician. 2007;10(1):213-28.

86. Boswell MV, Colson JD, Sehgal N, et al. A systematic review of therapeutic facet joint interventions in chronic spinal pain. Pain Physician. 2007;10:229-53.

87. Fuchs S, Erbe T, Fischer HL, et al. Intraarticular hyaluronic acid versus glucocorticoid injections for nonradicular pain in the lumbar spine. J Vasc Interv Radiol. 2005;16:1493-8.

88. Carette S, Marcoux S, Truchon R, et al. A controlled trial of corticosteroid injections into facet joints for chronic low back pain. N Engl J Med. 1991;325:1002-7.

89. Manchikanti L, Pampati VS, Bakhit C, et al. Effectiveness of lumbar facet joint nerve blocks in chronic low back pain: a randomized clinical trial. Pain Physician. 2001;4:101-17.

90. Pereira PL, Gunaydin I, Trubenbach J, et al. Interventional MR imaging for injection of sacroiliac joints in patients with sacroiliitis. Am J Roentgenol. 2000;175:265-6.

91. Maugars Y, Mathis C, Berthelot JM, et al. Assessment of the efficacy of sacroiliac corticosteroid injections in spondylarthropathies: a double-blind study. Br J Rheumatol. 1996;35(8):767-70.

92. Hansen HC, McKenzie-Brown AM, Cohen SP, et al. Sacroiliac joint interventions: a systematic review pain physician. 2007;10(1):165-84.

93. Wichman HJ. Discography: over 50 years of controversy. WMJ. 2007;106(1):27-9.

94. Katz JN, Lipson SJ, Chang LC, et al. Seven to ten year outcome of decompressive surgery for degenerative lumbar spinal stenosis. Spine. 1996;21:92.

95. Ibrahim T, Tleyjeh IM, Gabbar O. Surgical versus non-surgical treatment of chronic low back pain: a meta-analysis of randomized trials. In: International orthopedics. Available via SpringerLink. 2006. http://www.springerlink.com/content/b9634 hh822764233/. Accessed 21 Nov 2006. 